\title{
Expression and characterization of recombinant human milk fat globule-EGF factor VIII
}

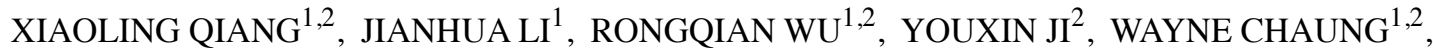 \\ WEIFENG DONG ${ }^{2}$ and PING WANG ${ }^{1,2}$ \\ ${ }^{1}$ The Feinstein Institute for Medical Research; ${ }^{2}$ Department of Surgery, North Shore \\ University Hospital and LIJ Medical Center, Manhasset, NY 11030, USA
}

Received June 28, 2011; Accepted August 8, 2011

DOI: $10.3892 /$ ijmm.2011.782

\begin{abstract}
Apoptosis plays an important role in the pathobiology of sepsis. The opsonizing protein milk fat globule-EGF factor VIII (MFG-E8) is involved in apoptotic cell clearance. Our previous studies have shown that administration of rat MFG-E8-containing exosomes or recombinant murine MFG-E8 (rmMFG-E8) is protective in a rat model of sepsis induced by cecal ligation of puncture (CLP). However, one obstacle hampering the development of MFG-E8 as a therapeutic agent for septic patients is the potential immunogenicity of animal proteins in humans. The purpose of this study, therefore, was to express recombinant human MFG-E8 (rhMFG-E8) and characterize its biological activity. Using an $E$. coli system, we successfully expressed and purified the mature molecule of human MFG-E8 (Leu24-Cys387). The purity of rhMFG-E8 was over $99 \%$ and it was immunoreactive for specific antihuman MFG-E8 antibodies. Amino acid sequence analysis by LC-MS/MS identified the purified protein as human MFG-E8. Using primary rat peritoneal macrophages, we showed that rhMFG-E8 markedly increased peritoneal macrophage phagocytosis of apoptotic thymocytes, which was as effective as commercial rmMFG-E8. To determine the biological activity of rhMFG-E8 in vivo, male adult rats were subjected to sepsis by CLP. rhMFG-E8 or rmMFG-E8 were administered intravenously at the time of CLP. Our results demonstrated that both rhMFG-E8 and rmMFG-E8 reduced thymocyte apoptosis and plasma levels of lactate and IL-6 at $20 \mathrm{~h}$ after CLP, and improved the 10-day survival rate. Thus, we have successfully expressed and purified biologically active rhMFG-E8. Our newly-expressed rhMFG-E8 is highly effective in the rat model of sepsis.
\end{abstract}

Correspondence to: Dr Ping Wang, Laboratory of Surgical Research, The Feinstein Institute for Medical Research, 350 Community Drive, Manhasset, NY 11030, USA

E-mail: pwang@nshs.edu

Key words: milk fat globule-EGF factor VIII, phagocytosis, apoptosis, sepsis, tissue injury, survival

\section{Introduction}

Sepsis is one of the most prevalent diseases and accounts for $20 \%$ of all admissions to intensive care units (ICUs) (1). Evidence indicates that in the US alone, more than 750,000 people develop sepsis each year with an overall mortality rate of $28.6 \%$ (1). Despite advances in the management of septic patients, a large number of such patients die of the ensuing septic shock and multiple organ failure (2-5). An analysis of hospital records indicates that the total number of patients who have died of sepsis is actually increasing (4). As the American population ages, the incidence of sepsis is projected to increase since the incidence and mortality rate of sepsis rise steadily with aging $(1,4)$. Thus, there is an urgent unmet medical need for an effective novel therapy for patients with sepsis.

Milk fat globule-EGF factor VIII (MFG-E8), also known as lactadherin in humans, is a glycoprotein originally identified as a component of milk fat globules that bud from the mammary epithelia during lactation. It is an important milk mucin-associated defense component that inhibits enteric pathogen binding and infectivity (6). Recent studies have shown that MFG-E8 can also be secreted by activated macrophages and immature dendritic cells and has been linked to the opsonization of apoptotic cells (7-11). It promotes the engulfment of apoptotic cells by working as a bridging molecule between apoptotic cells and phagocytes.

Our previous studies have shown that administration of rat MFG-E8-containing exosomes or recombinant murine MFG-E8 (rmMFG-E8) increases phagocytosis of apoptotic cells, reduces proinflammatory cytokines, and improves survival in a rat model of sepsis induced by cecal ligation of puncture (CLP) $(12,13)$. However, one obstacle hampering the development of MFG-E8 as a therapeutic agent for septic patients is the potential immunogenicity of animal proteins in humans. The purpose of this study, therefore, was to express recombinant human MFG-E8 (rhMFG-E8) and characterize its biological activity both in vitro and in vivo.

\section{Materials and methods}

Expression of recombinant human MFG-E8. A 1095 bp fragment encoding the mature region of human MFG-E8 (364 amino acids, R24-R387, SwissProt no. Q08431) was 
obtained by polymerase chain reaction amplification of a plasmid template containing the human MFG-E8 cDNA. The open reading frame was cloned into the SalI and NotI site of the pET-28a(+) vector (Novagen, Madison, WI) downstream of the phage T7 RNA polymerase promoter. The final protein product contained six histidines fused to the N-terminus of human MFG-E8. The plasmid was transformed into E. coli BL21 (DE3) cells. The cells were grown at $37^{\circ} \mathrm{C}$ in $2 \mathrm{YT}$ medium (Invitrogen) with kanamycin overnight. The rhMFG-E8 protein production was induced by the addition of isopropyl$\beta$-D-thiogalactopyranoside (IPTG) to a final concentration of $1.0 \mathrm{mM}$ and cell growth continued for $5 \mathrm{~h}$ at $25^{\circ} \mathrm{C}$. The cells were harvested by centrifugation and the induced rhMFG-E8 protein was purified according to the manufacturer's instructions (Novagen). The rhMFG-E8 fractions were pooled and the endotoxin of the protein solution was removed by phase separation using Triton X-114 (14). The content of LPS in the sample was determined using the Limulus Amebocyte lysate assay (BioWhittaker, Inc., Walkersville, MD) as previously described (15). The purity of rhMFG-E8 was evaluated by SDS-PAGE on a $10-20 \%$ Tris- $\mathrm{HCl}$ gel and visualized using the GelCode Blue Stain Regent (Pierce, Rockford, IL). The final product was concentrated by Amicon Ultra-15 Centrifugal Filter Devices to the designed concentration and stored at $-20^{\circ} \mathrm{C}$.

Mass spectrometry. The amino acid sequence of the isolated and purified protein was analyzed by LC-MS/MS at the Proteomics Resource Center of the Rockefeller University (New York, NY). Briefly, the sample was reduced with $5 \mathrm{mM}$ DTT and alkylated with $10 \mathrm{mM}$ iodoacetamide, and then digested with sequence grade modified trypsin (Promega) in ammonium bicarbonate buffer at $37^{\circ} \mathrm{C}$ overnight. The digestion products were analyzed by LC-MS/MS. For LC-MS/MS analysis, the digestion product was separated by gradient elution with the Dionex capillary/nano-HPLC system and analyzed by the Applied Biosystems QSTAR XL mass spectrometer using information-dependent, automated acquisition. The acquired $\mathrm{ms} / \mathrm{ms}$ spectra were converted to a Mascot acceptable format and searched using the Mascot database search algorithm. The allowed variable modifications for database searching were oxidation of methionines.

Western blot analysis of rhMFG-E8. Purified rhMFG-E8 proteins were electrophoretically fractionated on a $10-20 \%$ Tris- $\mathrm{HCl}$ gel under reducing conditions, transferred to a $0.45-\mu \mathrm{m}$ nitrocellulose membrane, and blocked with $5 \%$ non-fat dry milk in phosphate-buffered saline. Afterward, the membrane was incubated with 1:1,000 polyclonal antibody to human MFG-E8 (R\&D Systems, Minneapolis, MN) overnight at $4^{\circ} \mathrm{C}$. The blots were then incubated with horseradish peroxidase-linked anti-rabbit immunoglobulin G (1:10,000, Cell Signaling Technology, Beverly, MA) for $1 \mathrm{~h}$ at room temperature. A chemiluminescent peroxidase substrate (ECL, Amersham Biosciences, Piscataway, NJ) was applied according to the manufacturer's instructions, and the membranes were exposed briefly to radiography film.

Phagocytosis assay. This assay was conducted according to our previously described protocol (16). Briefly, freshly collected peritoneal macrophages from normal adult Sprague-Dawley rats were cultured in Dulbecco's modified Eagle's medium (DMEM; Gibco Life Technologies, Carlsbad, CA) containing $10 \%$ heat-inactivated exosome-free fetal bovine serum (FBS), $10 \mathrm{mM}$ 4-(2-hydroxyethyl)-1-piperazineethanesulfonic acid (HEPES), $100 \mathrm{U} / \mathrm{ml}$ penicillin and $100 \mathrm{mg} / \mathrm{ml}$ streptomycin at $37^{\circ} \mathrm{C}$ in a humidified atmosphere containing $5 \% \mathrm{CO}_{2}$. Cells were plated at a density of $2.5 \times 10^{4} /$ well in a 16 -well chamber slide (Nunc International, Rochester, NY). For all experiments, cells were kept at $80-90 \%$ confluence. Freshly collected thymocytes were cultured at a concentration of $10^{7}$ cells $/ \mathrm{ml}$ in RPMI substituted with $10 \%$ heat-inactivated FBS, $10 \mathrm{mM}$ HEPES, $100 \mathrm{U} / \mathrm{ml}$ penicillin, $100 \mathrm{mg} / \mathrm{ml}$ streptomycin, and $0.1 \mu \mathrm{M}$ dexamethasone for $16-24 \mathrm{~h}$ at $37^{\circ} \mathrm{C}$ and $5 \% \mathrm{CO}_{2}$. This produced $100 \%$ of apoptotic cells as assessed by Annexin V/ propidium iodide (PI) staining and analyzed by FACS. After being washed twice with Hank's balanced salt solution (HBSS, Gibco), the apoptotic thymocytes were resuspended in OPTI-MEM (Gibco) and incubated with or without rhMFG-E8 $(0.5 \mu \mathrm{g} / \mathrm{ml})$ or rmMFG-E8 $(0.5 \mu \mathrm{g} / \mathrm{ml})$ for $30 \mathrm{~min}$. Then the cells were incubated with $20 \mathrm{ng} / \mathrm{ml} \mathrm{pHrodo}$ succinimidyl ester (SE) (Invitrogen) for $30 \mathrm{~min}$. After washing, the cells were fed to cultured macrophages at the ratio of 4:1 (apoptotic cells/macrophages) for $1.0 \mathrm{~h}$. Then, adherent macrophages were washed twice with PBS and incubated with FITC-anti-rat CD11b/c (OX42; BD Pharmingen) for $20 \mathrm{~min}$. This staining provided a homogenous surface staining of macrophages and was useful to distinguish the surface of macrophages during analysis. The cells were then fixed with $1 \%$ paraformaldehyde for $15 \mathrm{~min}$ at $4^{\circ} \mathrm{C}$, transferred to PBS and kept at $4^{\circ} \mathrm{C}$ until analysis by fluorescent microscopy using a Nikon Eclipse E600 fluorescent microscope (Japan). The number of apoptotic cells and of macrophages that engulfed apoptotic cells were expressed as a ratio of apoptotic cells/macrophages (phagocytosis index).

Animal model of sepsis. Male Sprague-Dawley rats (275-325 g) were housed in a temperature-controlled room on a 12-h light/ dark cycle and fed a standard Purina rat chow diet. Prior to the induction of sepsis, rats were fasted overnight, but allowed access to water ad libitum. Rats were anesthetized with isoflurane inhalation and the ventral neck, abdomen and groin were shaved and washed with $10 \%$ povidone iodine. Cecal ligation and puncture (CLP) was performed as previously described (17-19). Briefly, a $2 \mathrm{~cm}$ midline abdominal incision was performed. The cecum was exposed, ligated just distal to the ileocecal valve to avoid intestinal obstruction, punctured twice with an 18-gauge needle, squeezed slightly to allow a small amount of fecal matter to flow from the holes, and then returned to the abdominal cavity, following which the abdominal incision was closed in layers. Immediately after CLP, a femoral vein was cannulated with a PE-50 tubing under anesthesia (isoflurane inhalation). The animal received a bolus injection of rhMFG-E8 $(20 \mu \mathrm{g} / \mathrm{kg} \mathrm{BW})$ in a volume of $1 \mathrm{ml}$ normal saline via the femoral venous catheter. Positive control animals received commercial rmMFG-E8 $(20 \mu \mathrm{g} / \mathrm{kg}$ BW). Vehicle-treated animals received a non-specific human plasma protein (i.e., human albumin) at the time of CLP. Sham-operated animals (i.e., control animals) underwent the same procedure with the exception that the cecum was neither ligated nor punctured. The animals were resuscitated with 


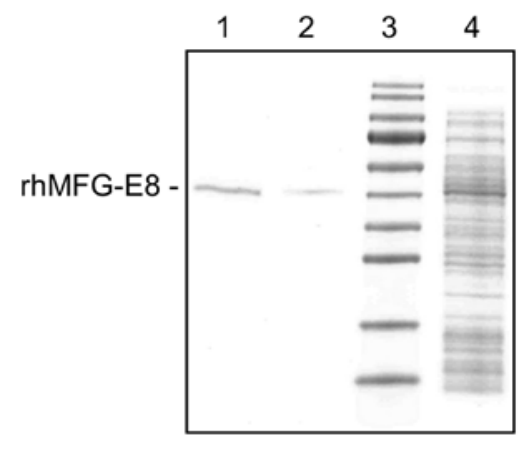

Figure 1. SDS-PAGE analysis of the expressed and purified rhMFG-E8. Lane 1, purified rhMFG-E8 $(1 \mu \mathrm{g})$; lane 2, purified rhMFG-E8 $(0.5 \mu \mathrm{g})$; lane 3 , marker; lane 4 , unpurified bacterial lysis.

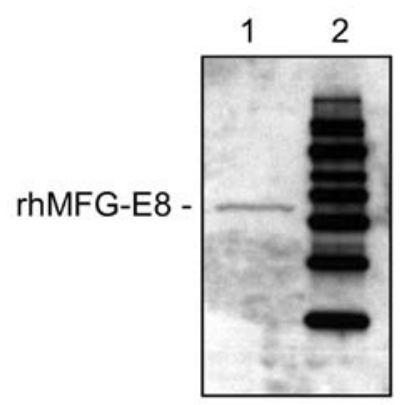

Figure 2. Western blot analysis of the expressed and purified rhMFG-E8. The specific anti-human antibody recognizes MFG-E8 by Western blot analysis. Lane 1, purified rhMFG-E8 $(1 \mu \mathrm{g})$; lane 2, marker.

$3 \mathrm{ml} / 100 \mathrm{~g}$ BW normal saline subcutaneously immediately after surgery. The animals were then returned to their cages. All experiments were performed in accordance with the National Institutes of Health guidelines for the use of experimental animals. This project was approved by the Institutional Animal Care and Use Committee (IACUC) of the Feinstein Institute for Medical Research.

Determination of thymocyte apoptosis. Thymocyte apoptosis was assessed by Annexin V/PI staining and Western blot analysis of cleaved caspase- 3 protein expression. Briefly, the fresh thymus was harvested at $20 \mathrm{~h}$ after CLP or sham operation. Thymocytes were isolated as previously described (16). The cells were stained using the Annexin V Fluos staining kit (Boehringer Mannheim, Indianapolis, IN) according to the manufacturer's instruction and analyzed by flow cytometry with FACSCalibur (BD Biosciences). The Annexin $\mathrm{V}^{+}$-PI' cells were considered as apoptotic cells. Cleaved caspase-3 protein expression was measured by Western blot analysis similar to the method for rhMFG-E8 protein analysis, as described above. Specific antibodies against cleaved caspase-3 protein (Cell Signaling, Danvers, MA) were used. $\beta$-actin was used as the loading control.

Determination of serum levels of lactate and IL-6. Serum concentrations of lactate were determined by using the assay kit according to the manufacturer's instructions (Pointe Scientific, Lincoln Park, MI). Serum levels of IL-6 were measured using

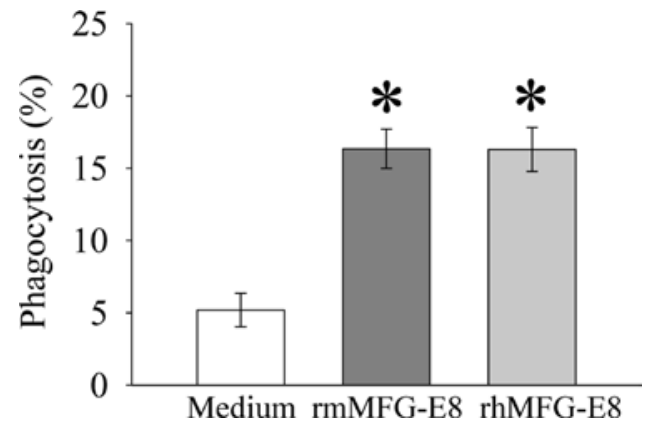

Figure 3. rhMFG-E8 potentiates phagocytosis of apoptotic cells. Fluorescent intensity of pHrodo-SE-labeled apoptotic thymocytes increases after engulfment by macrophages. Splenic macrophages were labeled with FITC anti-CD11b/c and thymocytes with pHrodo-SE. Cells were co-incubated for $60 \mathrm{~min}$, collected and fixed with 1\% PFA prior to fluorescent microscopy. The phagocytosis index of CD11b/c+pHrodo+ cells is shown. Data are presented as means \pm SE ( $n=6-9 /$ group) and compared by one-way ANOVA and the Student Newman-Keuls test, ${ }^{*} \mathrm{P}<0.05$ vs. medium alone.

a commercially available enzyme-linked immunosorbent assay (ELISA) kit (BioSource International, Camarillo, CA) according to the manufacturer's instruction.

Survival study. In additional groups of animals, vehicle (human albumin), rhMFG-E8 or rmMFG-E8 (20 $\mu \mathrm{g} / \mathrm{kg} \mathrm{BW})$ was administered immediately after CLP as described above. At $20 \mathrm{~h}$ after CLP, the gangrenous cecum was surgically excised and the peritoneal cavity was irrigated twice with $20 \mathrm{ml}$ warm, sterile saline solution. The abdominal incision was then closed in layers, and rats received $3 \mathrm{ml} / 100 \mathrm{~g} \mathrm{BW}$ saline subcutaneously. The animals were then returned to their cages and allowed food and water ad libitum. The changes in survival were monitored for 10 days.

Statistical analysis. All data are expressed as means $\pm \mathrm{SE}$ and compared by one-way analysis of variance (ANOVA). When the ANOVA was significant, post-hoc testing of differences between groups was performed using the Student NewmanKeuls test. The survival rate was estimated by Kaplan-Meier method and compared by the log-rank test. A P-value $<0.05$ was considered statistically significant.

\section{Results}

Expression and purification of rhMFG-E8. Using the E. coli system, we successfully expressed and purified rhMFG-E8. The SDS-PAGE analysis showed a single band at approximately $46 \mathrm{kDa}$ (Fig. 1). The purity of rhMFG-E8 was $>99 \%$ according to SDS-PAGE method (Fig. 1). The endotoxin level in the recombinant protein sample was not detectable as measured by the Limulus Amebocyte Lysate method (data not shown). Western blot analysis showed that purified rhMFG-E8 was immunoreactive for specific anti-human MFG-E8 antibodies (Fig. 2). Amino acid sequence analysis by LC-MS/MS showed that the purified protein was identified as human MFG-E8 with more than $95 \%$ confidence.

rhMFG-E8 increases the phagocytosis of apoptotic cells in vitro. Using peritoneal macrophages isolated from normal 


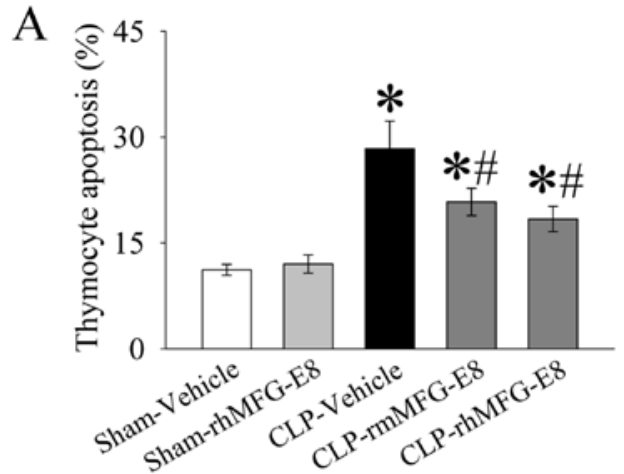

B

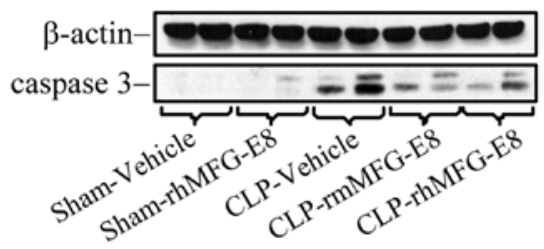

Figure 4. rhMFG-E8 reduced thymocyte apoptosis after CLP. Rats underwent CLP to induce experimental sepsis and were treated with human albumin (vehicle), rmMFG-E8 (20 $\mu \mathrm{g} / \mathrm{kg} \mathrm{BW})$, or rhMFG-E8 (20 $\mu \mathrm{g} / \mathrm{kg} \mathrm{BW})$ immediately after CLP. (A) Thymocyte apoptosis was assessed $20 \mathrm{~h}$ after CLP by Annexin V/PI staining and FACS analysis. Data are presented as means $\pm \mathrm{SE}$ ( $n=4$ /group) and compared by one-way ANOVA and the Student NewmanKeuls method: ${ }^{*} \mathrm{P}<0.05$ vs. the sham group; ${ }^{\prime} \mathrm{P}<0.05$ vs. the vehicle group. (B) Alterations in cleaved caspase- 3 in the thymus were determined by Western blot analysis at $20 \mathrm{~h}$ after CLP. Representative gels of two independent observations are presented.

rats, we have shown that rhMFG-E8 $(0.5 \mu \mathrm{g} / \mathrm{ml})$ markedly increased peritoneal macrophage phagocytosis of apoptotic thymocytes as compared to medium control $(\mathrm{P}<0.05)$ (Fig. 3). Moreover, our test indicated that rhMFG-E8 is as effective as commercial rmMFG-E8 in the rat (Fig. 3). Thus, the purified rhMFG-E8 effectively increases the clearance of apoptotic cells in vitro.

rhMFG-E8 reduces apoptosis and tissue injury in a rat model of sepsis. To determine the biological activity of the newly-expressed rhMFG-E8 in vivo, we examined its effect in a rat model of CLP. As shown in Fig. 4A, thymocyte apoptosis at $20 \mathrm{~h}$ after CLP increased by $153 \%$ relatively to vehicle-treated animals. Administration of rmMFG-E8 or rhMFG-E8 decreased sepsis-induced thymocyte apoptosis by 27 and $35 \%$, respectively, relative to the CLP-vehicle $(\mathrm{P}<0.05)$. However, rhMFG-E8 had no effect on thymocyte apoptosis in sham-operated animals. These findings were confirmed by protein levels of cleaved caspase-3 (an indictor of cell apoptosis) in the thymus (Fig. 4B). Serum levels of lactate, a marker for systemic hypoxia, increased by $60 \%$ at $20 \mathrm{~h}$ after CLP. Administration of rhMFG-E8 decreased lactate levels by $19 \%(\mathrm{P}<0.05)$ (Fig. 5A). Similarly, serum levels of IL-6, an organ injury indicator as well as a marker for inflammation, increased by $457 \%$ at $20 \mathrm{~h}$ after CLP. Administration of rmMFG-E8 or rhMFG-E8 decreased IL-6 levels by 46 and $38 \%$, respectively $(\mathrm{P}<0.05)$ (Fig. 5B).

rhMFG-E8 decreases sepsis-induced mortality in rats. To determine the long-term effect of rhMFG-E8 in sepsis, a 10-day

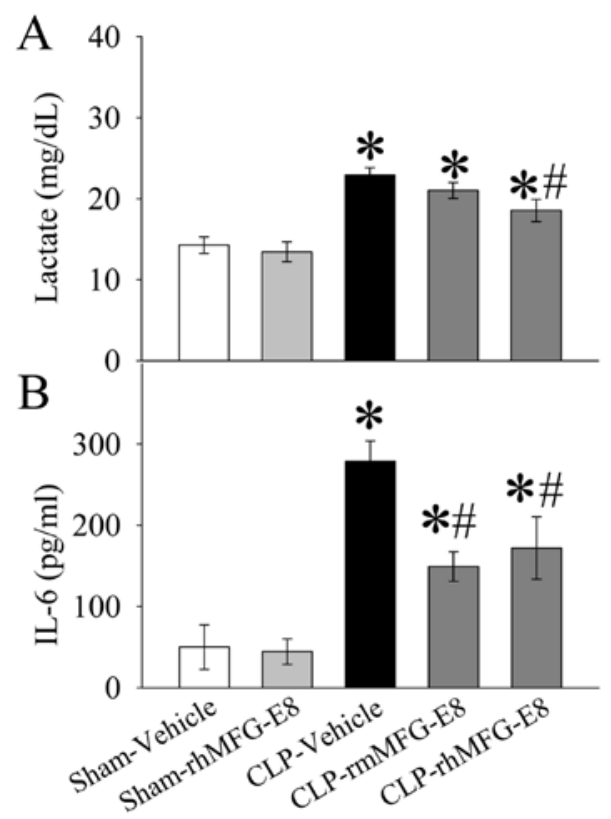

Figure 5. rhMFG-E8 attenuated organ injury after CLP. Rats underwent CLP to induce experimental sepsis and were treated with human albumin (vehicle), rmMFG-E8 (20 $\mu \mathrm{g} / \mathrm{kg} \mathrm{BW})$ or rhMFG-E8 $(20 \mu \mathrm{g} / \mathrm{kg} \mathrm{BW})$ immediately after CLP. Serum levels of (A) lactate and (B) IL-6 were measured at $20 \mathrm{~h}$ after CLP. Data are presented as means $\pm S E$ ( $n=4-6 /$ group) and compared by oneway ANOVA and the Student Newman-Keuls method: ${ }^{*} \mathrm{P}<0.05$ vs. the sham group; ${ }^{\#} \mathrm{P}<0.05$ vs. the vehicle group.

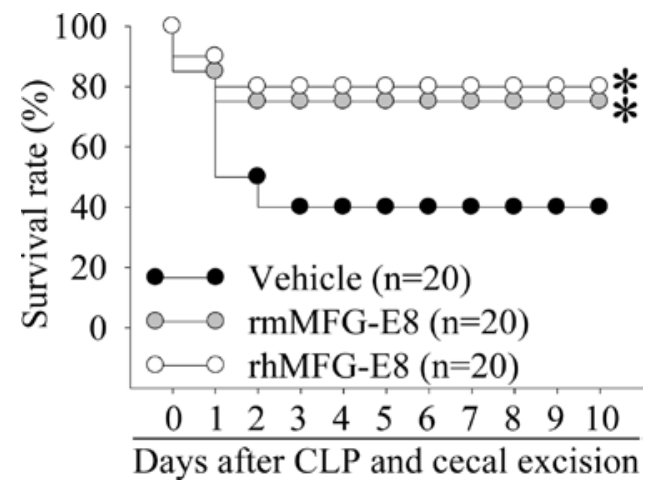

Figure 6. Alterations in the survival rate at 10 days after cecal ligation and puncture and cecal excision with human albumin treatment (vehicle), rmMFG-E8 (20 $\mu \mathrm{g} / \mathrm{kg} \mathrm{BW})$ or rhMFG-E8 $(20 \mu \mathrm{g} / \mathrm{kg} \mathrm{BW})$ treatment. There were 20 animals in each group. The survival rates were estimated by the Kaplan-Meier method and compared by using the log-rank test. ${ }^{*} \mathrm{P}<0.05$ vs. the vehicle group.

survival study was conducted. As shown in Fig. 6, the survival rate after CLP and cecal excision in vehicle (albumin)-treated animals was $50 \%$ on Day 2, and decreased to $40 \%$ on Days 3-10. Administration of rmMFG-E8 or rhMFG-E8 improved the survival rate to 75 and $80 \%$, respectively $(\mathrm{P}<0.05)$ (Fig. 6).

\section{Discussion}

Sepsis is a common, expensive, and frequently fatal condition. Although a great deal of preclinical and clinical trials have been carried out testing the efficacy and safety of various anti-sepsis agents (e.g., anti-cytokine and anti-endotoxin 
antibodies, steroids, antithrombin, insulin and inhibition of apoptosis), these investigations have not resulted in the development of effective clinical treatments (2-5). Apoptosis plays an important role in the pathobiology of sepsis (20-25). Reduction of apoptosis by overexpression of the anti-apoptotic $\mathrm{Bcl}-2$ protein or inhibition of pro-apoptotic molecules such as caspases, Fas-ligand, TNF-R or TRAIL has been proven to be beneficial in septic animals (26-31). In addition to the increased incidence of apoptosis, the phagocytic function is impaired in sepsis (32-35). Our previous studies have shown that down-regulation of MFG-E8 is responsible for the reduced phagocytosis of apoptotic cell in sepsis $(12,13)$. Administration of rat MFG-E8-containing exosomes or rmMFG-E8 increases phagocytosis of apoptotic cells, reduces proinflammatory cytokines, and improves survival in a rat model of sepsis $(12,13)$. The biological effect of this molecule has been confirmed using the MFG-E8 knockout animal model (13). Similarly, $\mathrm{Bu}$ et al (36) have shown that sepsis-triggered intestinal injury was associated with a down-regulation of intestinal MFG-E8 and treatment with rmMFG-E8 promoted mucosal healing in septic mice. Thus, MFG-E8 appears to be a leading candidate for treating septic patients.

Human MFG-E8 shares only 59, 57 and 53\% amino acid (aa) sequence identity with porcine, rat and mouse MFG-E8, respectively (http://blast.ncbi.nlm.nih.gov). In order to move forward this technology into the preclinical and clinical development, human MFG-E8 is required. However, the extremely high cost of commercial human MFG-E8 (using the murine myeloma cell line by R\&D Systems) limits its further development. In the current study, we have successfully expressed and purified rhMFG-E8 using an E. coli system at a much lower cost ( $>95 \%$ less expensive). The human MFG-E8 gene is located on chromosome $15 \mathrm{q} 25$ and is composed of eight exons. Human MFG-E8 protein is synthesized as a 387 aa precursor that contains a 23 aa signal sequence and a 364 aa mature region. The protein we have expressed is the mature molecule of human MFG-E8 (i.e., Leu24-Cys387) with an N-terminal 6-His tag. Native MFG-E8 is a glycoprotein. Since our rhMFG-E8 was expressed in an E. coli system, it has no glycosylation. As demonstrated by this study, our E. coli-derived rhMFG-E8 is as effective as the rmMFG-E8 expressed in the murine myeloma cell line (R\&D Systems). Our E. coli-derived rhMFG-E8 markedly increased peritoneal macrophage phagocytosis of apoptotic thymocytes and reduced thymocyte apoptosis and plasma levels of lactate and IL-6 at $20 \mathrm{~h}$ after CLP. Most importantly, administration of our E. coli-derived rhMFG-E8 improved the survival rate after CLP. Apparently, the glycosylation may not be essential for the biological function of MFG-E8.

The mature molecule of human MFG-E8 contains four $\mathrm{N}$-linked glycosylation sites, an amino-terminal EGF-like domain, plus $\mathrm{C} 1$ and $\mathrm{C} 2 \mathrm{Ig}$-like domains which are related to discoidin I and are homologous to those of human coagulation factors V and VIII (37,38). The EGF like domain contains the 'RGD-motif' (the amino acid sequence: Arg-Gly-Asp), which is strategically placed in a hairpin loop between two antiparallel $\beta$ strands $(37,38)$. In this way, the EGF like domain serves as a scaffold for the RGD sequence, which is proposed to promote cell adhesion by binding cell surface integrin receptors, such as $\alpha v \beta 3$ or $\alpha v \beta 5$ (39-41). The coagulation factor V/VIII like domains bind to phosphatidylserine (PS) exposed on the surface of apoptotic cells (42). Binding of MFG-E8 to PS on apoptotic cells opsonizes them for a complete engulfment by macrophages via $\alpha v \beta 3$ - or $\alpha v \beta 5$-integrins. Without MFG-E8, full engulfment and the removal of apoptotic cells cannot be completed (8). Apoptosis has been considered as an orderly process of cell suicide that does not elicit inflammation (43). However, recent discoveries have shown that apoptotic cells eventually undergo secondary necrosis and stimulate an inflammatory response if they are not removed by phagocytosis $(44,45)$. The lack of clearance of apoptotic B-cells in the spleen potentially leads to autoimmune diseases $(7,8)$. Similar phenomenons were also reported in the acute inflammatory environment such as sepsis $(13,46)$. In a recent study, pretreatment of animals with apoptotic splenocytes worsens the outcome of sepsis (46), pointing out the detrimental effect of apoptotic cells in the septic organism. Our current study also confirms the importance of apoptotic cell clearance in the pathogenesis of sepsis.

In summary, we have successfully expressed and purified biologically active rhMFG-E8. Our newly-expressed rhMFG-E8 is highly effective in the rodent model of sepsis. To the best of our knowledge, we are the only group that has investigated the potential role of the promotion of apoptotic cell clearance by MFG-E8 on the treatment of sepsis.

\section{Acknowledgements}

This study was supported by National Institutes of Health grants. We thank the Proteomics Resource Center of the Rockefeller University (New York, NY) for their kind help with the mass spectrometry analysis of our samples.

\section{References}

1. Angus DC, Linde-Zwirble WT, Lidicker J, Clermont G, Carcillo J and Pinsky MR: Epidemiology of severe sepsis in the United States: analysis of incidence, outcome, and associated costs of care. Crit Care Med 29: 1303-1310, 2001.

2. Ferrer R, Artigas A, Levy MM, Blanco J, Gonzalez-Diaz G, Garnacho-Montero J, Ibanez J, Palencia E, Quintana M and de la Torre-Prados MV: Improvement in process of care and outcome after a multicenter severe sepsis educational program in Spain. JAMA 299: 2294-2303, 2008

3. Strehlow MC, Emond SD, Shapiro NI, Pelletier AJ and Camargo CA Jr: National study of emergency department visits for sepsis, 1992 to 2001. Ann Emerg Med 48: 326-331, 2006.

4. Martin GS, Mannino DM, Eaton S and Moss M: The epidemiology of sepsis in the United States from 1979 through 2000. N Engl J Med 348: 1546-1554, 2003.

5. Guidet B, Aegerter P, Gauzit R, Meshaka P and Dreyfuss D: Incidence and impact of organ dysfunctions associated with sepsis. Chest 127: 942-951, 2005.

6. Yolken RH, Peterson JA, Vonderfecht SL, Fouts ET, Midthun K and Newburg DS: Human milk mucin inhibits rotavirus replication and prevents experimental gastroenteritis. J Clin Invest 90: 1984-1991, 1992.

7. Hanayama R, Tanaka M, Miwa K, Shinohara A, Iwamatsu A and Nagata S: Identification of a factor that links apoptotic cells to phagocytes. Nature 417: 182-187, 2002.

8. Hanayama R, Tanaka M, Miyasaka K, Aozasa K, Koike M, Uchiyama $Y$ and Nagata S: Autoimmune disease and impaired uptake of apoptotic cells in MFG-E8-deficient mice. Science 304: 1147-1150, 2004.

9. Miyasaka K, Hanayama R, Tanaka M and Nagata S: Expression of milk fat globule epidermal growth factor 8 in immature dendritic cells for engulfment of apoptotic cells. Eur J Immunol 34: 1414-1422, 2004. 
10. Thery C, Regnault A, Garin J, Wolfers J, Zitvogel L, RicciardiCastagnoli P, Raposo G and Amigorena S: Molecular characterization of dendritic cell-derived exosomes. Selective accumulation of the heat shock protein hsc73. J Cell Biol 147: 599-610, 1999.

11. Oshima K, Aoki N, Kato T, Kitajima K and Matsuda T: Secretion of a peripheral membrane protein, MFG-E8, as a complex with membrane vesicles. Eur J Biochem 269: 1209-1218, 2002.

12. Miksa M, Amin D, Wu R, Jacob A, Zhou M, Dong W, Yang WL, Ravikumar TS and Wang P: Maturation-induced down-regulation of MFG-E8 impairs apoptotic cell clearance and enhances endotoxin response. Int J Mol Med 22: 743-748, 2008

13. Miksa M, Wu R, Dong W, Komura H, Amin D, Ji Y, Wang Z, Wang H, Ravikumar TS, Tracey KJ and Wang P: Immature dendritic cell-derived exosomes rescue septic animals via milk fat globule epidermal growth factor VIII. J Immunol 183: 5983-5990, 2009.

14. Aida Y and Pabst MJ: Removal of endotoxin from protein solutions by phase separation using Triton X-114. J Immunol Methods 132 191-195, 1990

15. Li J, Wang H, Mason JM, Levine J, Yu M, Ulloa L, Czura CJ, Tracey KJ and Yang H: Recombinant HMGB1 with cytokinestimulating activity. J Immunol Methods 289: 211-223, 2004.

16. Miksa M, Komura H, Wu R, Shah KG and Wang P: A novel method to determine the engulfment of apoptotic cells by macrophages using pHrodo succinimidyl ester. J Immunol Methods 342: 71-77, 2009.

17. Wu R, Dong W, Zhou M, Zhang F, Marini CP, Ravikumar TS and Wang P: Ghrelin attenuates sepsis-induced acute lung injury and mortality in rats. Am J Respir Crit Care Med 176: 805-813, 2007.

18. Cui X, Wu R, Zhou M, Simms HH and Wang P: Differential expression of cytochrome P450 isoforms in the lungs of septic animals. Crit Care Med 32: 1186-1191, 2004.

19. Wu R, Dong W, Cui X, Zhou M, Simms HH, Ravikumar TS and Wang P: Ghrelin down-regulates proinflammatory cytokines in sepsis through activation of the vagus nerve. Ann Surg 245: 480-486, 2007.

20. Hotchkiss RS and Nicholson DW: Apoptosis and caspases regulate death and inflammation in sepsis. Nat Rev Immunol 6: 813-822, 2006.

21. Remick DG: Pathophysiology of sepsis. Am J Pathol 170: 1435-1444, 2007.

22. Lang JD and Matute-Bello G: Lymphocytes, apoptosis and sepsis: making the jump from mice to humans. Crit Care 13: 109, 2009.

23. Pinheiro da Silva F and Nizet V: Cell death during sepsis: integration of disintegration in the inflammatory response to overwhelming infection. Apoptosis 14: 509-521, 2009.

24. Ward PA: Sepsis, apoptosis and complement. Biochem Pharmacol 76: 1383-1388, 2008.

25. Ayala A, Perl M, Venet F, Lomas-Neira J, Swan R and Chung CS: Apoptosis in sepsis: mechanisms, clinical impact and potential therapeutic targets. Curr Pharm Des 14: 1853-1859, 2008.

26. Hotchkiss RS, Coopersmith CM and Karl IE: Prevention of lymphocyte apoptosis - a potential treatment of sepsis? Clin Infect Dis 41 (Suppl 7): S465-S469, 2005.

27. Wesche DE, Lomas-Neira JL, Perl M, Chung CS and Ayala A: Leukocyte apoptosis and its significance in sepsis and shock. J Leukoc Biol 78: 325-337, 2005.

28. Wesche-Soldato DE, Chung CS, Lomas-Neira J, Doughty LA, Gregory SH and Ayala A: In vivo delivery of caspase- 8 or Fas siRNA improves the survival of septic mice. Blood 106: 2295-2301, 2005.

29. Ayala A, Lomas JL, Grutkoski PS and Chung S: Fas-ligand mediated apoptosis in severe sepsis and shock. Scand J Infect Dis 35: 593-600,2003.
30. Zhou M, Simms HH and Wang P: Adrenomedullin and adrenomedullin binding protein-1 attenuate vascular endothelial cell apoptosis in sepsis. Ann Surg 240: 321-330, 2004.

31. Bommhardt U, Chang KC, Swanson PE, Wagner TH, Tinsley KW, Karl IE and Hotchkiss RS: Akt decreases lymphocyte apoptosis and improves survival in sepsis. J Immunol 172: 7583-7591, 2004.

32. Gregory SH and Wing EJ: Neutrophil-Kupffer cell interaction: a critical component of host defenses to systemic bacterial infections. J Leukoc Biol 72: 239-248, 2002.

33. Zhang P, Bagby GJ, Stoltz DA, Summer WR and Nelson S: Enhancement of peritoneal leukocyte function by granulocyte colony-stimulating factor in rats with abdominal sepsis. Crit Care Med 26: 315-321, 1998.

34. Gutierrez-Fernandez J, Maroto MC, Piedrola G and Zamora E: Dysfunction of the mononuclear phagocytic system in sepsis. APMIS 97: 441-446, 1989.

35. Angle N, Cabello-Passini R, Hoyt DB, Loomis WH, Shreve A, Namiki S and Junger WG: Hypertonic saline infusion: can it regulate human neutrophil function? Shock 14: 503-508, 2000.

36. Bu HF, Zuo XL, Wang X, Ensslin MA, Koti V, Hsueh W, Raymond AS, Shur BD and Tan XD: Milk fat globule-EGF factor 8/lactadherin plays a crucial role in maintenance and repair of murine intestinal epithelium. J Clin Invest 117: 3673-3683, 2007.

37. Couto JR, Taylor MR, Godwin SG, Ceriani RL and Peterson JA Cloning and sequence analysis of human breast epithelial antigen BA46 reveals an RGD cell adhesion sequence presented on an epidermal growth factor-like domain. DNA Cell Biol 15: 281-286, 1996.

38. Taylor MR, Couto JR, Scallan CD, Ceriani RL and Peterson JA: Lactadherin (formerly BA46), a membrane-associated glycoprotein expressed in human milk and breast carcinomas, promotes Arg-Gly-Asp (RGD)-dependent cell adhesion. DNA Cell Biol 16: 861-869, 1997.

39. Akakura S, Singh S, Spataro M, Akakura R, Kim JI, Albert ML and Birge RB: The opsonin MFG-E8 is a ligand for the alphavbeta5 integrin and triggers DOCK180-dependent Racl activation for the phagocytosis of apoptotic cells. Exp Cell Res 292: 403-416, 2004.

40. Zullig S and Hengartner MO: Cell biology. Tickling macrophages, a serious business. Science 304: 1123-1124, 2004.

41. Ait-Oufella H, Kinugawa K, Zoll J, Simon T, Boddaert J, Heeneman S, Blanc-Brude O, Barateau V, Potteaux S, Merval R, Esposito B, Teissier E, Daemen MJ, Leseche G, Boulanger C, Tedgui A and MallatZ: Lactadherin deficiency leads to apoptotic cell accumulation and accelerated atherosclerosis in mice. Circulation 115: 2168-2177, 2007.

42. Veron P, Segura E, Sugano G, Amigorena S and Thery C: Accumulation of MFG-E8/lactadherin on exosomes from immature dendritic cells. Blood Cells Mol Dis 35: 81-88, 2005.

43. Fadok VA, Bratton DL, Konowal A, Freed PW, Westcott JY and Henson PM: Macrophages that have ingested apoptotic cells in vitro inhibit proinflammatory cytokine production through autocrine/ paracrine mechanisms involving TGF-beta, PGE2, and PAF. J Clin Invest 101: 890-898, 1998.

44. Bell CW, Jiang W, Reich CF III and Pisetsky DS: The extracellular release of HMGB1 during apoptotic cell death. Am J Physiol Cell Physiol 291: C1318-C1325, 2006.

45. Scaffidi P, Misteli T and Bianchi ME: Release of chromatin protein HMGB1 by necrotic cells triggers inflammation. Nature 418: 191-195, 2002.

46. Hotchkiss RS, Chang KC, Grayson MH, Tinsley KW, Dunne BS, Davis CG, Osborne DF and Karl IE: Adoptive transfer of apoptotic splenocytes worsens survival, whereas adoptive transfer of necrotic splenocytes improves survival in sepsis. Proc Natl Acad Sci USA 100: 6724-6729, 2003. 